\title{
Raising the quality of local journals: some insights and observations
}

\author{
Ramanathan Subramaniam \\ Singapore National Academy of Science and Nanyang Technological University, Singapore
}

\section{Introduction}

The rapid pace at which developments in science and technology are occurring as well as the need to disseminate such findings in respectable scholarly platforms is putting tremendous pressure on academic institutions (including academic staff) to rise to the challenges. The journal is the most prized platform for publishing scholarly work. Among journals in a field, there is also a ranking order-the higher its ranking, the more highly regarded it is. Naturally, academics who are able to publish in top journals are highly regarded. However, not all manuscripts submitted to journals get accepted. In fact, for prestigious journals, the acceptance rate can be as low as about $10 \%$ to $20 \%$. This is one of the reasons for the proliferation of journals within a discipline. If only well-established journals in a discipline are considered to be the platforms for publication, then very little will ever get published, and scholarly pursuits will be severely affected-and this will be a setback for the human and scientific enterprise. It is in this context that local journals do have a role to play in the dissemination of scientific research.

The principal objectives of this paper are to share some insights and observations on how to raise the quality of local journals-it could mean either existing journals or new journals about to be launched. These insights and observations are drawn from my own experience in editorial work as well as observations of a number of scientific and education journals over the years. As regards my experience in editing, I wish to cite the following:

I was one of the managing editors of COSMOS (flagship journal of the Singapore National Academy of Science), published by World Scientific Publishing, for a few years since its first publication; I was guest editor of the International Journal of Technology Management (UK) for their special issue on science \& technology centers; I was guest co-editor of the International Journal of Technology Management (UK) for their special issue on scientific academies \& scientific societies; And, I was guest co-editor of COSMOS for their special issue on science education. In addition, I have co-edited 4 books for international publishers.

Ramanathan Subramaniam http://orcid.org/0000-0002-4789-9063

This paper is based on a presentation at the 2nd Asian Science Editors Conference and Workshop, Hanoi, Vietnam, August 20-22, 2015.

\section{Current Status of Journals Published from Asia}

In the current publication landscape, journals published from Asia are generally lagging behind other journals published from the developed world when it comes to various metrics 
science editing /

such as impact factors and citations. Many journals published from Asia have not yet been featured in the Web of Science. There seems to be some skepticism even among Asian authors in wanting to submit to local journals even if one were available in their specialty. Academics would naturally want to submit their best work to international journals in the United States of America and Europe as these are well established. It is unlikely that academics would want to submit their best work to a local journal. Publications in leading international journals count more during annual appraisal of academics. The influence of impact factors of journals and emphasis on citations of papers are very high in many universities-thus, it is understandable if academics' preference is for submissions to international journals.

What we have to note, however, is that many established journals started off by catering mainly to the local scientific community. In due course, they were able to attain international recognition through sheer hard work by the editors and also from the high quality of submissions published. This means journals published from Asia can improve their international ranking if strategic thinking is employed by the journals' editorial boards.

\section{On the Need for Local Journals}

There are currently about 20,000 universities in the world, and new ones are being established regularly. While universities serve the primary role of providing tertiary education in various fields to students, research is also an important aspect of their mission. Publications are the primary currency by which the research work of academics are judged. Clearly, the research output emerging from all these institutions cannot be fulfilled if recourse is placed only on publishing in well-established journals. International journals have low acceptance rates and can only publish a limited number of papers annually. Local journals have thus a role to play in supporting capacity building in developing countries [1]. Such journals are still needed to support scholarly pursuits in a discipline, especially in the developing world.

Many universities in the developing world face funding constraints with regards to research, which means that they will have difficulties doing cutting edge research and publishing such work. It would not be surprising if a number of academics in many of these universities engage in basic research or on research that can be supported by limited funds. For example, study of the local flora and fauna can be an important area of fundamental research, and such research does not generally require large funding. Fundamental research on the local flora and fauna is less likely to be of interest to major international journals-and this is where local journals still have a role to play in supporting such research. Science education research, especially those related to certain aspects of teaching and learning in classrooms, is another area for such research and one that can be done with limited or modest funding.

Local journals in the various disciplines play an important role in ensuring that universities in the countries they originate from have additional outlets to support academic research in these areas as well as publishing graduate students' work. With the pronounced emphasis placed on science and technology in today's society and their role in economic development [2], building competencies in the various sciences in a country is very important. At the tertiary level, scholarship in these sciences is also important, and local journals have an important role to play in this regard, especially in developing countries in Asia.

\section{Some Tips for Raising Quality of Local Journals}

In this section, some tips are provided for raising the quality of local journals. The local journals could either be existing ones or those that are about to be started. The tips are based on my observations of the international journal scene as well as my own experiences in editing journals. The tips are enumerated as follows:

1. A core group of people with the vision and passion to drive local scientific output in a particular discipline must come forward to realize the mission-either to revitalize an existing journal or to start a new journal in a discipline. There needs to be journals catering to a number of scientific disciplines in a developing country.

2. A leading researcher in the country with international connections needs to helm the discipline-specific scientific journal. Others can come in as associate editors or as members of the editorial board.

3. It is necessary for the journal to be linked to a leading scientific society in the country. This gives credibility to the journal and allows it to be differentiated from others. In fact, many of the major scientific journals are published by scientific societies.

4. The journal needs to be published in the English language, which is generally regarded as the language of science and technology. This does not mean the sidelining of the local language but instead is recognition of the realities of today's academic publishing landscape. Scientific publications in the English language can garner an international readership. If need be, the abstract can be presented in two languages-English and the local language. The latter has the advantage also of ensuring wider dissemination of the findings locally. 
5. It is necessary to have an international editorial board as well as reviewers. This may not be that easy for those journals that are new or are about to be started but it is a goal worth aspiring for. The network connections of local academics can be tapped on for this purpose. Not to be overlooked in this regard are the academic diaspora settled in the developed world.

6. Open access, online format for the journal is to be preferred rather than the print version as the latter is expensive and incurs mailing charges as well as problems related to storage and handling, which can also incur additional costs and/or inconveniences. The open access, online format can help to enhance the impact factor of the journal in the long run. It also provides free access to others. Quite a number of online journals are now included in the Web of Science, so this format is a viable option.

7. Regular frequency of publication is important-at least three or four issues a year, with each issue of about 5-7 papers, would be a useful goal. This may not be that easy in the early years, so the frequency of publication can be moderated somewhat in these years. In due course of time, once the reputation of the journal is established, the publication frequency can be increased.

8. It is important for the journal to have a good mix of local and international authors-the need to give upcoming local researchers an additional platform to submit their scholarly work and help them build up a portfolio cannot be underestimated.Opening outlets to academics from other countries, even those in other developing countries, can also help the journal to take off sooner and ensure a regular publication frequency.

9. After a few years when the journal has been reasonably well established, an overseas academic can be invited to be the guest editor for a special issue of the journal on a suitable topic Academics see merit in editing a special issue of a journal focusing on a topic of their specialty-they also see it as a kind of recognition to be invited to edit a special issue. By its very nature, special issues garner wider readership.

10. Peer review of manuscripts must not be compromised. Scientific rigor and scholarship are key factors in this regard. There should be at least two reviewers for each article. Acceptance rates should not be too high. Where possible, encouragement can be rendered to deserving authors in the process of revisions, even if this means taking a few rounds.

11. It will be great if internationally established academics in the country can contribute to the journal. They may not send their best work to local journals-even their second best may be good enough! Visiting academics can also be encouraged to contribute a suitable paper to the journal.
All these are some ways to raise the profile of the journal. It is essential to keep in mind the goal of getting the journal listed in the Web of Science within a reasonable period of time.

While funding is often an issue for journals, it can be circumvented to a good extent with some creative thinking-for example, going for web-based journals addresses problems related to printing, storage and handling of hard copies of journals. Hosting a journal on a website usually does not incur much expenses if it is kept as simple as possible. Funding can also be in kind. However, some funding would definitely be useful and needs to be raised-this can come through donations from well-wishers as well as through revenue from the organizing of suitable workshops by those who have a stake in the success of the journal.

It is essential to note that running a journal means a lot of work for editors as this is on top of their regular work and other commitments. They thus need good support so that they can focus more on the strategic positioning of the journal -otherwise they may be overwhelmed by journal work. This could be explored in the following ways:

1. Providing internship opportunities in editorial office work for graduate students on a part time basis would be an option worth exploring. This can greatly help to relieve editors' workload. To dignify the nature of such work, titles such as editorial assistant or webmaster can be offered to the graduate students for the period of their stint. Editorial assistance can be in areas such as tracking manuscripts, correspondence with authors, and follow-up with reviewers-all these usually take quite some time. Also, graduate students with proficiency in web-based publishing can help in design \& artwork as well as layout of the proof copy of the paper. An advantage of such titles is that the graduate students can acquire useful experience in the process and get to list this in their curriculum vitae-this can come in useful when they go for job interviews. It is necessary to give a good number of graduate students opportunities and experiences in such internships.

2. Involving graduate students from the English Language department in the local universities to help in copy-editing, if necessary, of accepted manuscripts of local authors can be explored if funding is hard to come by for professional copy-editing. In the long run, it is possible to build a good pool of copy editors from among these graduate students and whose services-especially those who excel in such work, can be sought after graduation for a nominal fee.

\section{Summarizing Comments}

With the proliferation of journals and the competition from 


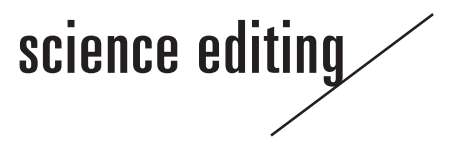

other established journals in the field, it is a challenge to publish a local journal or to continue an existing local journal. Local journals, however, do serve an important role in promoting scholarly publishing in developing countries, and it is necessary to continue this tradition. With established journals being able to publish only a fraction of the research that is being carried out, local journals have a role to play in providing further outlets for scholarly publishing in a country.

It has to be reiterated that this paper does not make a call for academics in developing countries to publish their work only in local journals. Submissions to international journals are still to be encouraged and are preferred. Given the voluminous output in research emerging from across the world; and the fact that only a limited amount of work can be published in international journals, it is clear that local journals do have a role to play in this regard in providing additional publication platforms for authors in developing countries. Good work done in a field by local academics and that are not accepted in established international journals still need an outlet-local journals can come in useful in this regard, provided, of course, the manuscripts pass the reviewers' scrutiny. All these efforts also contribute towards endogenous capacity building in developing countries. Getting the journal recognized internationally within a period of time and having it included in the
Web of Science should be a goal worth aspiring for.

\section{Conclusion}

It is suggested in this article that there is a role for local journals to play in developing countries, including those in Asia, and that it is possible to raise the profile of these journals to an international level if stakeholders can work harder and strategically to help realize this vision. Some observations and perspectives have been shared in this paper.

\section{Conflict of Interest}

No potential conflict of interest relevant to this article was reported.

\section{References}

1. Tan WHL, Subramaniam R. Challenges facing developing countries in communicating science to the public. In: Tan WHL, Subramaniam R, editors. Communicating science to the public: opportunities and challenges for the AsiaPacific region. New York, NY: Springer; 2014. p. 213-22.

2. Tan WHL, Subramaniam R. Developing countries need to popularise science. New Sci 1988;2139:52. 